\title{
The Cultivation of Reading and Thinking for College Students Existential Dilemma and Exploration
}

\author{
Li Ning ${ }^{1, a}$ \\ ${ }^{1}$ School of Mechanical Engineering, Shandong Huayu University of Technology, Dezhou Shandong \\ a625026376@qq.com
}

\begin{abstract}
Contemporary college students are born in the Internet era, and there is a general situation that students in various universities do not read enough and do not think deeply, such as lack of reading classics and in-depth thinking. Reading is the key source of acquiring knowledge. Students can be absorbed in reading and immerse themselves in it, experience the relaxation and immersive in books, develop students' reading potential and stimulate their interest in reading. Thinking is to continue to understand deeply and find problems from it, ask questions, exercise the degree of active thinking, to develop a good habit of thinking. Under the Internet environment, all kinds of information spreads rapidly through the network, and all kinds of fragmentary and superficial information comes one after another. The Network has the characteristics of fast reading transmission, diversified forms and fragmented reading, and modern audio-visual products are popular. Reading traditional classic works requires students to think deeply from multiple perspectives. If college students indulge in shallow reading pleasure brought by Internet media for a long time, it will not only be difficult to cultivate the ability of independent thinking and analysis of college students, but also affect the results of college education.
\end{abstract}

Keywords: Reading and Thinking, Nurturance education, Dilemma and Exploration

\section{大学生阅读与思考的养成教育中 存在的困境与探索}

李宁 $1, \mathrm{a}$

${ }^{1}$ 山东华宇工学院 机械工程学院, 德州, 山东

a625026376@qq.com

\section{摘要:}

当代大学生出生在互联网时代, 各类高校的学生普遍存在阅读不足、思考不深入的情况, 阅读经典名著和深入 思考欠缺 ${ }^{[1]}$ 。阅读是获取知识的关键来源, 学生在阅读中全神贯注并置身其中, 体验书中的悠然自得与身临其 境,开发学生的阅读潜能,激发阅读的兴趣。思考是不断地进行深入领会并从中发现问题,提出问题,锻炼思维活 跃程度,养成勤于动脑思考的好习惯。互联网环境下，各类信息通过网络快速传播，各类片段性与浅层化的信 息接踵而至，网络具有阅读传输快速化、形式多样化、阅读碎片化等特点，而且现代的视听类产品流行，传统 经典作品的阅读要求学生多角度的深度思考, 如果大学生长期沉溺于互联网媒体带来的浅层阅读快感, 不仅难 以培养出大学生作为个体独立思考分析的能力，还会影响大学教育的成果。

关链词: 阅读与思考 养成教育 困境与探索 


\section{1. 大学生阅读与思考的社会现状}

新时代背景下的大学生是建设社会主义国家的 中坚力量, 同时肩负着国家科技发展和文化发展, 青 年兴则国家兴，青年强则国家强。青年一代有理想、 有本领、有担当，国家就有前途，民族就有希望。

爱因斯坦曾讲过:"提出一个问题往往比解决一个 问题更为重要。"。如果大学生在阅读与思考的过程中 能把握住核心问题，可以自主善于阅读学习,勤于思 考, 对于学生自身发展至关重要。互联网时代, 众多 的搜索引擎、阅读终端让大学生的阅读方式更加多样 化、方便化。部分大学生阅读也呈现浅层化现象。新 媒体相对于传统的纸质阅读, 已逐渐成为当代大学生 查找信息资料、进行阅读的一种重要学习方式。移动 阅读新媒体时代改变了大学生的阅读生活, 当代大学 生减少了阅读纸质书籍。

习总书记的读书观包括“爱读书”“读好书”“善读 书”“会用书”“读书精”。对于高等学校的大学生而言, 阅读中华优秀传统文化的经典著作以及各学科专业 的经典论著是“最有价值的书”。经典论著是具有典范 性、权威性, 同时也具有深厚的文化积淀和人文内涵, 能够展现当时的思想文化传统，也代表了民族的精神 力量, 呈现着中华民族的理想信念。通过阅读经典著 作, 用知识武装大学生的头脑, 帮助学生树立正确的 世界观、人生观和价值观。

\section{2. 大学生阅读与思考的素质养成中的困境}

在新媒体时代, 当代大学生的阅读与思考能力显 得尤为重要 ${ }^{[2]}$ 。新媒体阅读扩展了大学生的课堂和专 业之外的一些相关知识, 可以有效充实自己, 提升自 己看待问题的能力。但是新媒体下的阅读具有实用化、 休闲化、功利化、碎片化等特点。新媒体下的阅读有 时候不能进行深层次思考。

\section{1. 大学生养成教育中勤于阅读习惯存在的问 题}

部分大学生沉迷于游戏中, 上课时漫不经心, 下 课后在宿舍中打游戏、玩手游等网络游戏。真正静心 阅读思考的时间很少, 再进行由阅读到意义生成的过 程是思考的过程更少。

\section{2. 大学生养成教育中深度阅读与思考能力的 缺失}

大学生的勤于阅读与善于思考的习惯是需要培 养和反复锻炼的, 大学生在学习阶段勤于阅读与善于 思考的习惯是一项不可或缺的能力。在专业领域的深 入学习中要深入仔细阅读, 锻炼阅读的速度与质量, 同时也要锻炼思考力, 提升专注于学业的注意力, 在 互联网下的大学生需要更强的自控力和外界辅助才 有可能做到专心专注的阅读与思考 ${ }^{[3]}$ 。

\section{3. 在培养学生在善于阅读与勤于思考中的难 点}

当代大学生受主客观因素与外界环境的限制,阅 读能力水平整体不高且参差不齐,部分学生没有养成 良好的阅读习惯、未能掌握正确的阅读方法, 无法形 成优秀的阅读思维,对阅读感到茫然失措, 从而产生 不屑、排斥心理,这将严重地制约学生专业学习。当代 大学生普遍存在的阅读主动性不高、学习性不强、目 的性不明等问题 $\left.{ }^{4}\right]$ 。

\section{3. 以 “五抓五强” 方式加强大学生阅读与 思考的习惯养成教育}

大学生勤于阅读与善于思考需要进一步细化、具 体化, 是学生专业学科核心素养培育的必要途径, 也是 解决当代大学生阅读能力普遍较弱的有效探索。大学 生自由时间与片段化时间较多, 选择合适的路径来引 导大学生合理高效利用自己的时间来练习阅读, 逐步 转变大学生的云阅读思路, 培养大学生开展深入阅读 并融合有价值的思考。

\section{1. 抓实思想教育，严把学生 “思想关”}

（1）强化价值导向, 提高认知能力。在大一新生 中通过集体班会和个别教育结合方式开展善于阅读 与勤于思考的养成习惯主题教育, 引导大学生了解深 入阅读、善于阅读的状态, 引导学生明确社会责任感 与历史使命感，确立集体主义观念，树立终身阅读与 思考的意识。其次, 对大学生进行个别教育, 逐个谈 心谈话。辅导员与学业导师共同引导大学生对专业知 识和中华文化底蕴的知识进行深入教育引导, 因材施 教地指导学生工作并帮助学生做好阅读规划。例如: 根据因沉迷游戏而无法自拔的、因工作而无时间阅读 的等不同类型的学生, 引导他们确定提升阅读能力的 改进目标, 不断改正不愿意阅读的习惯, 不断完善自 我。

(2) 强化目标导向, 提升规划意识。部分大学生 因社会责任感差、发展目标不明确, 抱着得过且过的 态度生活, 自我放纵, 学业较差。因此, 开展大学生 阅读与思考班会、锻炼静坐思考能力班会, 引导大学 生树立未来发展目标和大学四年的目标, 树立时间管 理意识。当大学生树立正确的人生观和价值观, 激发 强烈的社会责任感, 会加强自我管理和自我规划, 自 觉调节学习、工作和生活方式, 形成健康的时间管理 习惯, 脚踏实地地朝着目标努力。

（3）强化自律导向, 增强执行能力。大学生有了 理想信念的支撑, 人生目标的指引, 要形成善于阅读 与勤于思考的习惯, 关键在于其自身主观能动性的发 挥。大学宽松自由的学习环境, 使得大学生的自制力 减弱, 沉迷于网络游戏、手机、电脑。教师要关注学 生对目标的落实, 培养大学生的自律意识, 引导他们 通过自我调节、自我激励, 合理安排学习时间。引导 
大学生通过亲身践行, 体验阅读经典名著的好处, 提 升善于阅读与勤于思考养成的体验感, 自觉减少打游 戏玩手机的时间，运用自己的智慧去创造多彩的人生。

\section{2. 抓强载体建设, 搭建教育 “新平台”}

(1) 开展校园阅读月活动。一方面, 让学生在丰 富多彩的校园文化中潜移默化地接受善于阅读与思 考习惯的养成教育; 另一方面, 让学生在读书月活动 中体验读书的乐趣, 找到书中自有黄金屋, 书中自有 颜如玉的感觉, 培养善于阅读与深入思考的兴趣, 体 验成功的喜悦。例如: 结合世界读书日 (4月 23 日), 举行大学生读书日宣传周或宣传月, 以 “善于阅读与 勤于思考” 为主题, 开展读书比赛、背诵比赛、释义 比赛, 开展 “读书月, 看三本书” 的签名活动。邀请 专家开展阅读教育与动脑思考教育专题讲座, 增加大 学生对阅读方法了解的知识和增加积极阅读的意识。 除此之外, 我与班委组织过在一个学期内每周组织我 所带的 20 级本科学生进行 “晚自习阅读一小时” 与 “睡前读书半小时” 的活动, 积极鼓励提倡学生“爱读 书”“读好书”“善读书”“会用书”“读书精”, 促进学生养 成良好读书习惯, 增加阅读与思考的趣味性、参与性。

(2) 开展宿舍文化活动。部分高校的大学生因为 缺少学习兴趣或学习工作压力过大或自身自律情况, 无法做到按时阅读与按质阅读, 无法深入思考书中的 释义, 不断地通过打游戏、玩手机短视频、刷微博等 无意义的事情来浪费自己的时间, 虚度光阴。高校可 以开展宿舍文化品牌活动、宿舍读书会、宿舍文化节 等各种各样的系列活动来促进大学生阅读, 督促大学 生营造宿舍阅读舒适整洁的学习生活环境, 也帮助大 学生养成良好的生活作息习惯, 让学生在快乐氛围中 加强学习交流, 阅读与思考的习惯养成, 在宿舍有愉 悦放松的心情, 营造安静的读书学习氛围, 形成舍友 之间的良好人际关系, 舍友间谈笑风生中饱含文化诗 意, 凸显人格魅力 ${ }^{[5]}$ 。

(3) 搭建信息化平台。各大高校可以利用学校广 播、横幅、宣传栏等传统载体以大学生喜闻乐见的形 式进行鼓励学生善于阅读与勤于思考养成教育活动 的宣传。与此同时, 更要全面积极推进学生读书教育 与 “互联网” 深度融合, 形成 “云阅读” 模式。不断 探索创新互联网媒体和学生养成教育结合的新管理 形式。通过学校官网、官方微信公众号、官方微博、 官方抖音与快手等网络平台教育引导学生了解明白 阅读的意义, 让学生在各方面都能接受善于阅读与勤 于思考的健康学习方式的教育, 增强学生健康学习教 育信息化工作的吸引力和引导力。

\section{3. 抓牢学生干部队伍建设, 培养工作的 “好帮手”}

成立班级学生阅读与思考帮扶干部团队, 学生干 部团队既要负责学生阅读读物的日常读书考核, 也要 关注学生读书的质量与注重加强鼓励学生读专业知
识与经典名著、党史等书籍, 积极引导广大学生养成 善于阅读与勤于思考的学习方式。成立 “阅读监督小 组” 定期检查和不定期抽查, 督促学生提高自我提升 能力和自我管理能力, 主动把自己闲下来的时间专心 致志的阅读与思考, 定期通报检查结果, 以此与学生 评优评先挂钩, 并以奖励的方式鼓励学生多读书、读 好书。充分发挥思想素质硬的班长以及班干部、学生 党员等思想先进分子在学生群体中具有号召力强、影 响力大的优势特点, 向学生们传递阅读与思考下的正 能量, 做“爱读书”“读好书”“善读书”“会用书”“读书精” 的先行者, 带头学习习总书记学习的思想, 制定用于 阅读时间的时间表等, 积极带动身边同学广阅读、爱 阅读 ${ }^{[6]}$ 。发现不爱阅读或者扰乱阅读秩序的现象, 及 时向学业导师或者辅导员进行汇报, 从而精准及时解 决存在的学生不良行为等现象。

\section{4. 抓好典型示范, 树立善于阅读与勤于思 考的 “好榜样”}

针对班级常去图书馆借书并写读后感的同学或 者是常在网上购买并阅读专业知识以及经典著作类 的学生, 树立标杆并点名表扬, 在开班会时安排表现 优异的学生及时给班里其他同学分享读书的乐趣与 阅读的经验。例如不少学生都遇到注意力不集中问题, 他们会选择听音乐阅读。这些也可以让他们在学生们 中进行经验分享。对于阅读中有深入心得体会、学习 工作优秀的学生, 安排他们分享阅读对他们学习工作 的影响和静心阅读的方法。号召全校学生向身边典型 榜样学习, 启发他们对标先进, 找出自身差距, 进行 整改, 引导他们养成善于阅读与勤于思考的习惯, 激 发他们努力学习的精气神。

\section{5. 抓稳制度创新，推动管理 “精准化”}

部分高校制定了大学生养成教育管理规范制度, 例如规定大学生课前十分钟、睡前阅读半小时。辅导 员应严格落实执行, 确保制度落到实处。同时, 要创 新制度管理。例如: 实施学生第二课堂 “积分管理”, 与学生的评优评先挂钩。结合不同学生的实际情况, 推动学生阅读与思考的管理具体化: 对遵守规定的学 生实行 “规范管理”，对经常旷课或不按时参加课前 十分钟的学生实行 “档案管理”, 对不参与阅读与思 考的学生实行 “帮扶管理”。安排学生干部、党员对不 按时参加 “课前十分钟” 和 “睡前半小时” 学生结成 帮教对子, 针对帮扶对象存在的问题, 有针对性的帮 教，促进不断养成良好的阅读与思考习惯。

\section{4. 小结}

培养学生进行微阅读, 并时刻关注学生的个体反 应和合作表现,促使他们养成主动阅读、勤于思考、乐 于分享、勇于表达、善于倾听的良好学习习惯和品质 等 ${ }^{[7]}$ 。主要策略是要加强专业阅读与经典名著的阅读, 增强阅读的知识面, 扩宽阅读的广度;培养学生云阅 
读的观念并在云阅读的基础上做好笔记、锻炼深入思 考的能力, 积极转变云阅读只看小说或者只注重书本 知识, 经典著作应当以书本知识为主, 更新换代的知 识应当以知网等网络平台为主, 快速便捷的获得最新 的知识。灵活阅读的媒体, 增加学生阅读的时长与兴 趣。积极拓宽专业知识视野, 激发学生阅读的动力; 坚 持阅读方法训练, 注重阅读习惯培养。阅读能力的提 升是一个循序渐进的过程, 不可操之过急; 微阅读理解 与深入思考也需要时间沉淀, 不可急于求成。只要坚 持不解的练习并提升自己的阅读时长, 一定能够达到 阅读质量提升的预期目标。

\section{项目基金}

本文为学校教科研基金一般项目《应用型 本科高校大学生阅读与思考能力养成教育路 径探究》（2021YC17）的阶段性成果之一。

\section{REFERENCES}

[1] Hu M F. (2020) Characteristics of Reading behavior of College students and innovation

of reading service in University Libraries in the Era of "Internet plus". J. Heilongjiang Education (Higher Education Research and Assessment).56-58.

[2] Chen G L. (2019) Study on reading Behavior and Countermeasures of college students in Higher Vocational Colleges -- A case study of reading survey of students in 6 higher vocational colleges in Guangdong Province. J. Library journal.56-62.

[3] Hu L F.,Qiu Y. (2020) Research on micro-reading Behavior of Post-2000 College Students and its Guidance Strategy. J. Literature Education (I).93-95.

[4] Ying Z Y. (2019) A study on the Family responsibility of contemporary Youth and its Development. D. Nanjing: Nanjing University of Science and Technology.

[5] Liu J Y. (2018) Research on Chinese Spiritual Education of Contemporary College Students. D. Harbin: Northeast Forestry University.

[6] Zhang W Z. (2019) Study on the volunteer Service of college students in the New Era. D.Changchun: Northeast Normal University.

[7] Zhou J. (2019) Research on the cooperative mechanism of Red culture to cultivate socialist core Values. D.Nanchang: Jiangxi Normal University. 